\title{
Flexibility Study for a MSF by Monte Carlo Simulation
}

\author{
Enrique Tarifa, Samuel Franco Domínguez, \\ Carlos Vera and Sergio Mussati \\ Universidad Nacional de Jujuy, \\ Universidad Nacional del Litoral, CONICET, \\ Argentina
}

\section{Introduction}

Traditionally, processes and controllers are designed sequentially. Firstly, the process configurations (structures) and parameters are designed to satisfy the economic objectives, such as maximum profit or minimum operational costs. The designs are based on steady state models, and they are subjected to the operational constraints. Then, the controllers are designed, with a focus on rejecting the possible effects of external disturbances and process uncertainties, and achieving the desired dynamic performance. This approach carries a risk in that it may end up choosing the cheapest process design that can prove difficult to control. It may also miss out a slightly less economic but easier to control design, the one that might be more profitable in the long run (Weitz \& Lewin, 1996).

Operability properties of a process determine how process dynamics affect the quality of a process control design. These include flexibility, controllability, optimality, stability, selection of measurements and manipulated variables. The flexibility is defined as 'the ability to maintain the process variables within the feasible operational region, despite the presence of uncertainties' (Grossman et al., 1983). Flexibility is often considered simultaneously with the economic objectives and hence the optimality issue is raised. As a consequence, flexibility studies are dominated by numerous optimization strategies. Those studies aim at the determination of flexible operational spaces and flexibility measurements. The analysis generally involves two complementary tasks, the calculation of the flexibility index and the flexibility test.

Operational flexibility is an important issue when designing and operating a chemical plant. Very often, flexibility is concerned with the problem of ensuring a feasible steady-state operation over a variety of operating uncertainties. To quantify how flexible a process is many metrics have been developed. Grossmann et al. (1983) first introduced the flexibility index FIG which quantifies the smallest percentage of the uncertain parameters' expected deviation that the process can handle. Another metric named resilience index RI was adopted by Saboo et al. (1985). These two measurements -FIG and RI- require identification of the nominal point, which must be located within the feasible region. These measurements however only take the critical uncertainty into account. This may cause serious flexibility under-estimation or neglect the ability of the process to handle other process uncertainties. To solve this problem, Pistikopoulos and Mazzuchi (1990) proposed an index called 
stochastic flexibility, SF, that is determined from the probability distribution of all the uncertain parameters. Although $S F$ accounts for the chance that the process can operate feasibly, the probability distribution of all the uncertain parameters may not be available at the design stage. Even though the probability distributions can be obtained, the calculation of SF is usually tedious. To avoid this difficulty, Lai and Hui (2007) proposed the index FIV. This was calculated as the size ratio of the feasible space to the overall space bounded by the expected limits of the uncertain parameters. The feasible space is the subspace of the overall space in which the uncertain parameters can be feasibly handled. The index SF and FI belong to the interval $[0,1]$; a higher value means a higher flexibility.

In this work several flexibility indexes for a multi-stage flash (MSF) desalination plant were estimated. To mimic the plant operation a stationary simulator was developed, and the determination of the feasible space was carried out with Monte Carlo simulation (Metropolis \& Ulam, 1949; Rubinstein \& Kroese, 2007). This approach does not involve an optimization model, but only a simulation one; hence the implementation is more simple and robust than other approaches. Finally, the proposed method yields additional information besides the flexibility indexes, and the relevance of this additional information shows the potential of this approach.

\section{Mixing tank modelling}

The strategy of the proposed flexibility study will be introduced by using a simpler system, a mixing tank, as shown in Fig. 1 . In this system, stream $\mathrm{F}_{1}$, water at $25^{\circ} \mathrm{C}$, and stream $\mathrm{F}_{2}$, water at $80^{\circ} \mathrm{C}$, are mixed to yield a new stream at $52{ }^{\circ} \mathrm{C}$. The pressure at the valve $\mathrm{V}_{1}$ input is $1.115 \times 10^{5} \mathrm{~Pa}$. The volumetric flow rate of $F_{2}$ is $0.02 \mathrm{~m}^{3} / \mathrm{s}$. The tank is open and discharges to the atmosphere; its diameter is $1.5 \mathrm{~m}$ and the maximum allowed liquid level is $2 \mathrm{~m}$. The controller CT (a P+I controller) controls the tank temperature $T$, and the controller CL (a P controller) controls the tank level $L$; the respective set points are $52^{\circ} \mathrm{C}$ and $1 \mathrm{~m}$.

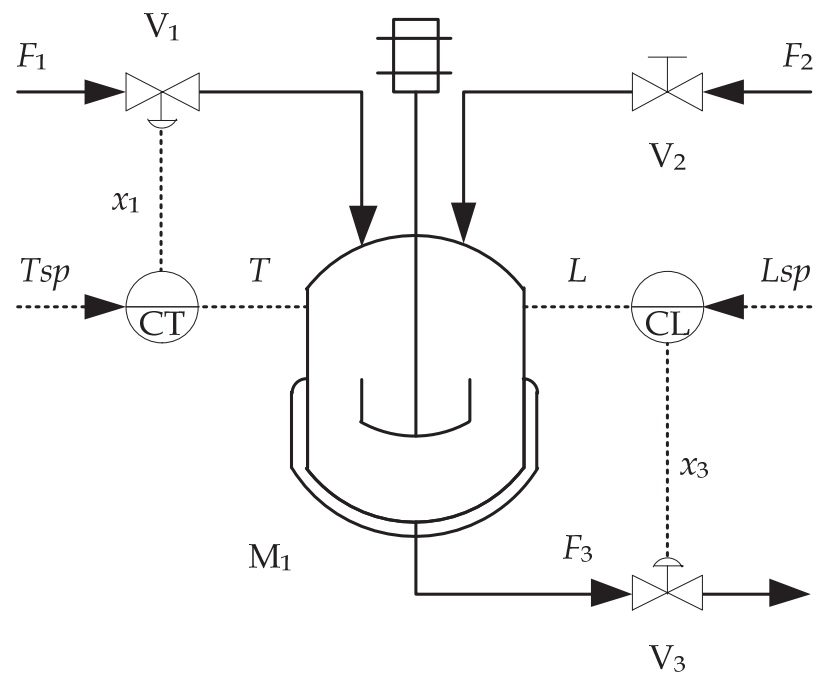

Fig. 1. Mixing tank. 
The dynamic model for the mixing tank comprises the following equations:

$$
\begin{gathered}
\frac{d L}{d t}=\frac{F_{1}+F_{2}-F_{3}}{A} \\
\frac{d T}{d t}=\frac{F_{1}\left(T_{1}-T\right)+F_{2}\left(T_{2}-T\right)}{A L} \\
\frac{d A i_{\mathrm{T}}}{d t}=e_{\mathrm{T}} \\
e_{\mathrm{T}}=T-T s p \\
x_{1}=A b_{\mathrm{T}}+K_{\mathrm{T}}\left(e_{\mathrm{T}}+\frac{1}{\tau i_{\mathrm{T}}} A i_{\mathrm{T}}\right) \\
e_{\mathrm{L}}=L-L s p \\
x_{3}=A b_{\mathrm{L}}+K_{\mathrm{L}} e_{\mathrm{L}} \\
F_{1}=C_{\mathrm{v} 1} x_{1} \sqrt{P_{1}-P_{0}} \\
F_{3}=C_{\mathrm{v} 3} x_{3} \sqrt{\rho g L}
\end{gathered}
$$

Table 1. presents the list of variables used in the previous model. The parameters of controller CT are $T s p=52{ }^{\circ} \mathrm{C}, A b_{\mathrm{T}}=0.5, K_{\mathrm{T}}=0.05{ }^{\circ} \mathrm{C}^{-1}$ and $\tau i_{\mathrm{T}}=30 \mathrm{~s}$; the parameters of controller CL are $L s p=1 \mathrm{~m}, A b_{\mathrm{L}}=0.5$ and $K_{\mathrm{L}}=20 \mathrm{~m}^{-1}$. The valve parameters are $C_{\mathrm{v} 1}=4.039 \times 10^{-4} \mathrm{~m}^{3.5} / \mathrm{kg}^{0.5}$ and $C_{\mathrm{v} 3}=8.078 \times 10^{-4} \mathrm{~m}^{3.5} / \mathrm{kg}^{0.5}$.

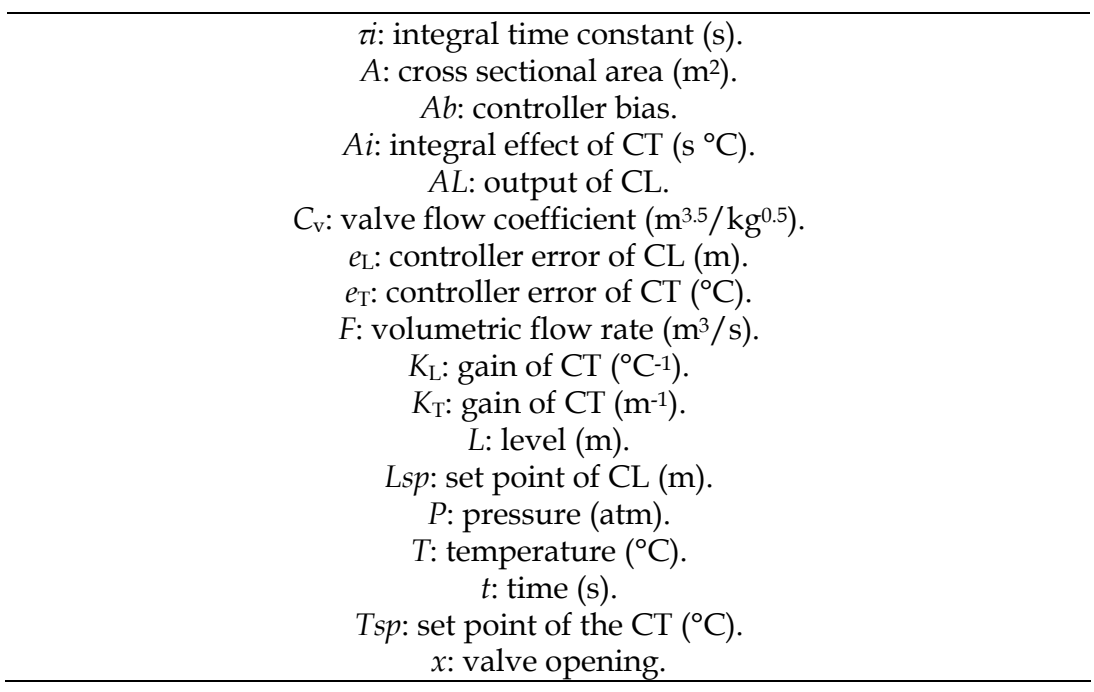

Table 1. Variables of the mixing tank model. 
The steady model is obtained from the dynamic one by setting to zero all the derivative terms. The resulting model contains 9 equations and 9 unknowns $\left(F_{1}, F_{3}, T, L, e_{\mathrm{T}}, x_{1}, e_{\mathrm{L}}, x_{3}\right.$ and $\left.A i_{\mathrm{T}}\right)$. If $T, e_{\mathrm{T}}, e_{\mathrm{L}}$ and $A i_{\mathrm{T}}$ are removed, the model can be reduced to the following equations:

$$
\begin{gathered}
F_{1}=F_{2} \frac{\left(T_{2}-T s p\right)}{\left(T s p-T_{1}\right)} \\
x_{1}=\frac{F_{1}}{C_{\mathrm{v} 1} \sqrt{P_{1}-P_{0}}} \\
F_{3}=F_{1}+F_{2}
\end{gathered}
$$

$L$ and $x_{3}$ are calculated from the two following equations:

$$
\begin{gathered}
x_{3} C_{\mathrm{v} 3} \sqrt{\rho g L}-F_{3}=0 \\
A b_{\mathrm{L}}+K_{\mathrm{L}}(L-L s p)-x_{3}=0
\end{gathered}
$$

\section{Standardization of variables}

In the proposed method every variable has to be standardized as follows:

$$
\delta X=\frac{X-X n}{\Delta X n}
$$

where $X$ is the actual value of the variable, $X n$ is the nominal value that was considered for the variable during the system design, and $\Delta X n$ is the half-band of acceptable variability for the variable. As it can be deduced, $\delta X$ is a dimensionless value that belongs to the open interval $(-1,1)$ under normal conditions, and it takes the null value at the nominal condition. This study considers two set of variables. The first set, called D, is formed by the disturbances; the second one, called $\mathrm{Y}$, is formed by the other process variables (i.e. all the variables of the process, disturbances not being included). In the case of the mixing tank, the selected disturbances are $F_{2}$ and $T_{2} ;$ whereas the selected process variables are $x_{1}$ and $x_{3}$.

\section{Overall and feasible spaces}

According to the above definitions, the overall space bounded by the expected limits of the uncertain parameters (Lai \& Hui, 2007) can be defined as:

$$
\left|\delta X_{j}\right| \leq 1 \quad \forall j \in \mathrm{D}
$$

On the other hand, the feasible space in which the uncertain parameters can be feasibly handled (and where the process is operable) can be defined as:

$$
\left|\delta X_{j}\right|<1 \quad \forall j \in \mathrm{Y}
$$


In order to determine whether the process is operable or not in a given point of the overall space, it is convenient to define the operability index in the following way:

$$
I o=\max _{j \in \mathrm{Y}}\left(\left|\delta \mathrm{X}_{j}\right|\right)
$$

While Io, the maximum observed deviation of the process variables, belongs to the interval $[0,1)$ the process is operable because the deviations of all process variables are lower than their respective acceptable variabilities. This index is used to determine the feasible space, which is formed by all the process states with Io belonging to the interval $[0,1)$.

Fig. 2 shows the overall space for two disturbances, $D_{1}$ and $D_{2}$. A square circumscribed about a circle of radius $r$ and centre $(0,0)$ is also shown in that figure. That square is called the maximum square if it is the largest square that can be defined in the feasible space.

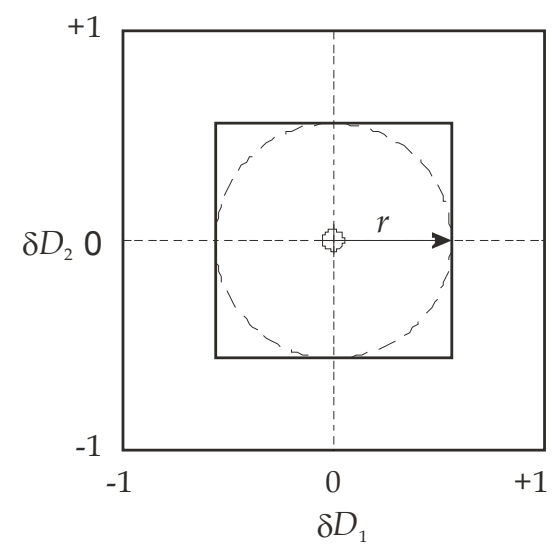

Fig. 2. Overall space and maximum square.

The probability that the disturbances yield a point inside the maximum square depends on the probability distributions associated to the disturbances. If every disturbance follows the uniform distribution (Fig. 3) that probability has the distribution plotted in Fig. 4. Conversely, if every disturbance follows the triangular distribution (Fig. 5) that probability has the distribution shown in Fig. 6. Both distributions (in Fig. 4 and Fig. 6) were obtained by Monte Carlo simulation with a sample of 10000 points (Metropolis \& Ulam, 1949; Rubinstein \& Kroese, 2007).

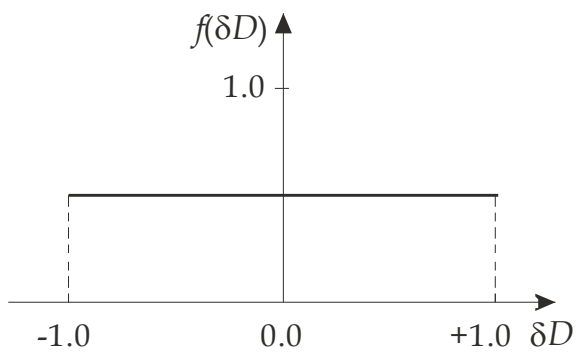

Fig. 3. Uniform distribution for $\delta D$. 


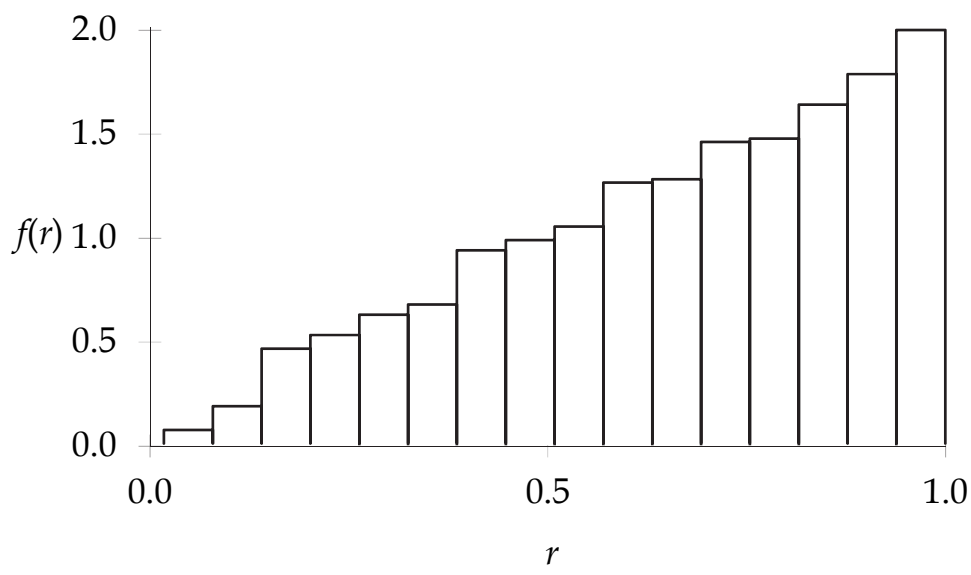

Fig. 4. Probability density distribution of $r$ for uniform distribution of $\delta D$. The median is 0.71 .

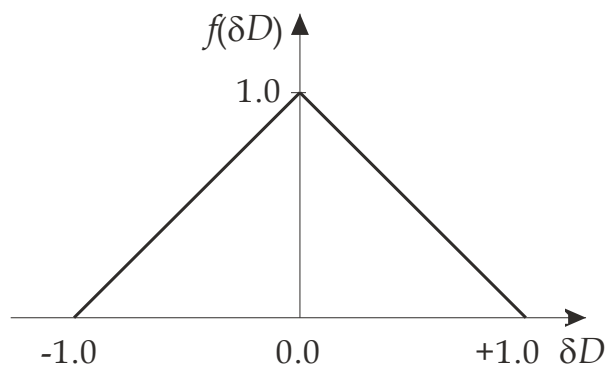

Fig. 5. Triangular distribution for $\delta D$.

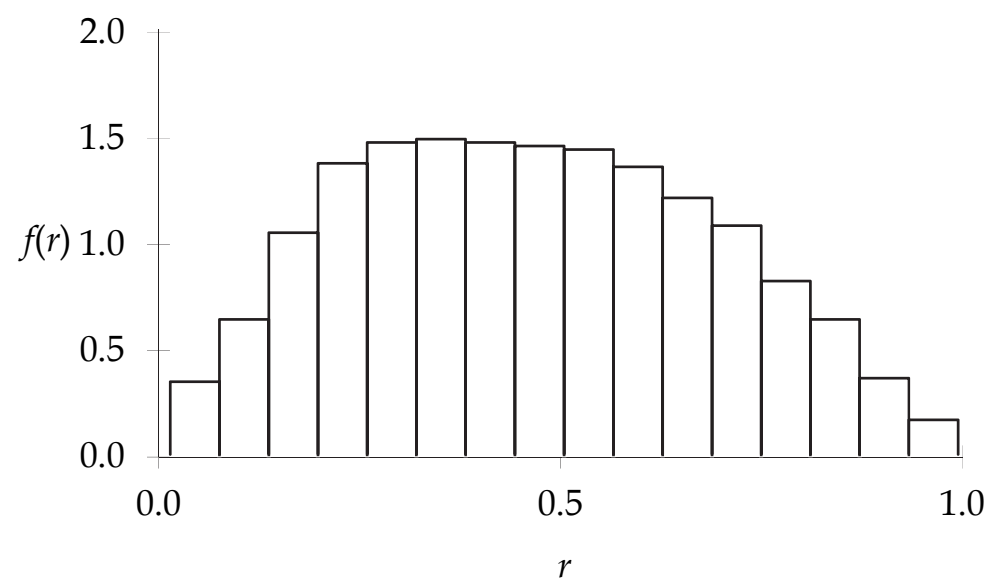

Fig. 6. Probability density distribution of $r$ for triangular distribution of $\delta D$. The median is 0.46 . 
For both the uniform and triangular distributions, it is possible to determine analytically the respective probability density function -pdf- $f(r)$ and the cumulative distribution function -cdf- $F(r)=\int_{0}^{r} f(t) d t$ (Rose \& Smith, 2002) associated to the maximum hypercube of dimension $n$ (maximum square if $n=2$ ). If every disturbance follows the uniform distribution, the corresponding pdf and cdf for the maximum hypercube of dimension $n$ are:

$$
\begin{gathered}
f(r)=n r^{n-1} \\
F(r)=r^{n}
\end{gathered}
$$

If every disturbance follows the triangular distribution, the corresponding pdf and cdf for the maximum hypercube of dimension $n$ are:

$$
\begin{gathered}
f(r)=2 n\left(r^{2}+2 r(1-r)\right)^{n-1}(1-r) \\
F(r)=\left(r^{2}+2 r(1-r)\right)^{n}
\end{gathered}
$$

Then, the probability that the combination of disturbances were constrained to the maximum square defined by $r$ is equal to $F(r)$.

If every disturbance follows a normal distribution (Fig. 7) the probability of the disturbances yielding a point inside the maximum square has the distribution plotted in Fig. 8. The distribution was obtained by Monte Carlo simulation with a sample of 10000 points. In contrast to the case of the uniform and triangular distributions, it is not possible to obtain analytical expressions of $f(r)$ and $F(r)$ when the disturbances are normally distributed. For this reason, Monte Carlo simulation was again used to determine $F(r)$ (Fig. 9). A good approximation for $F(r)$ is achieved by data regression, this approximation has a maximum error of 0.04 , and is equal to $F(r)=\exp \left(-3.6109(1-r)^{3.7664}\right)$.

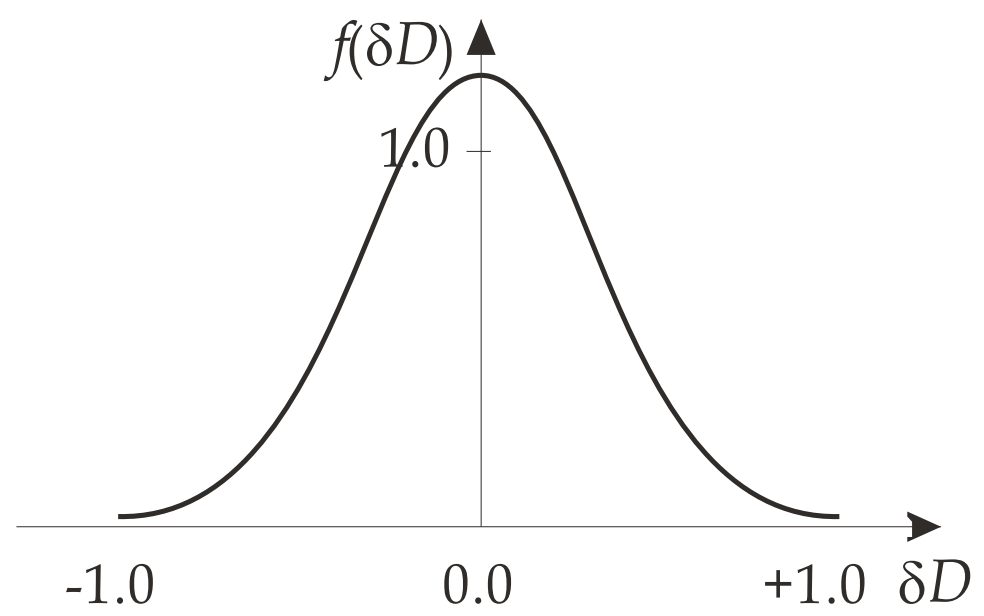

Fig. 7. Normal distribution for $\delta D$ with $\mu=0, \sigma=1 / 3$. 


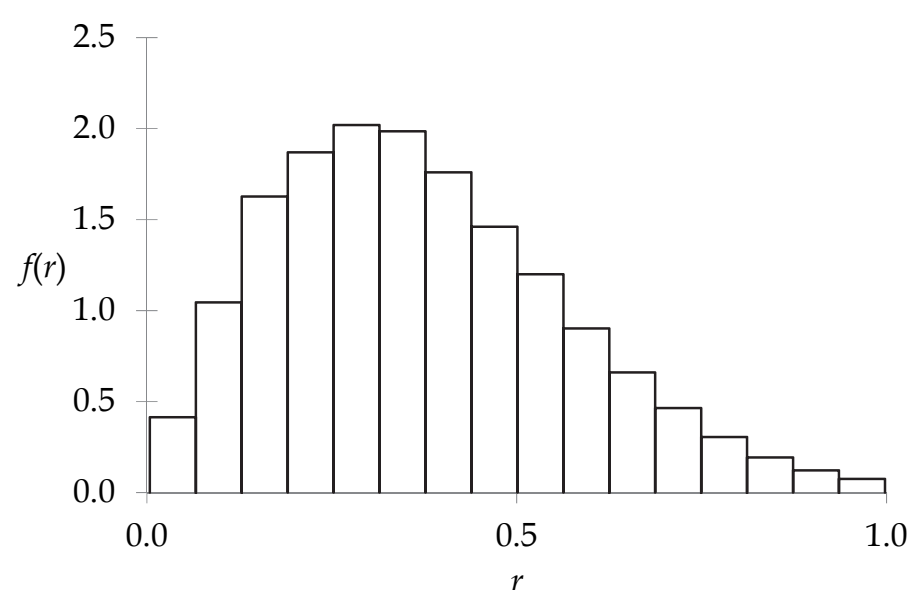

Fig. 8. Probability density distribution of $r$ for normal distribution of $\delta D$. The median is 0.35 .

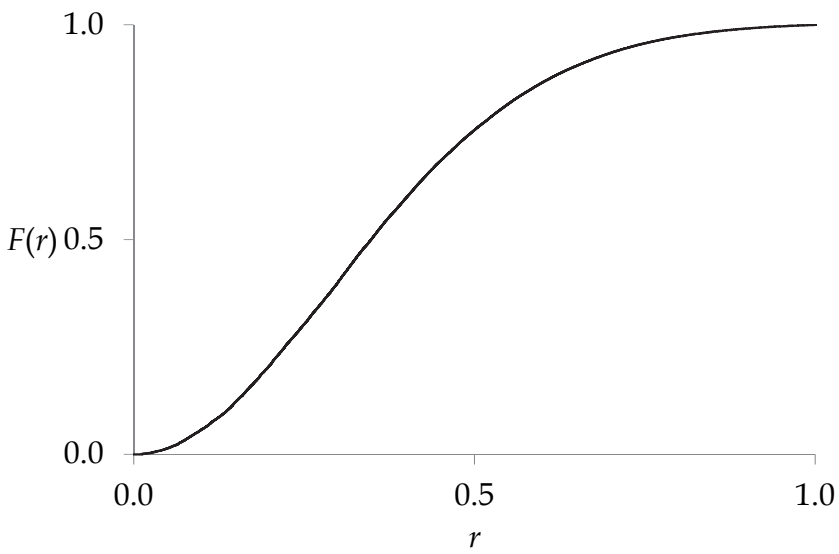

Fig. 9. Cumulative distribution function of $r$ for normal distribution of $\delta D$.

The maximum hypercube is useful because it makes it easy to verify whether a given operating point is inside it. This is a sufficient condition to guarantee the process operability. If the point is outside the maximum square, a deeper analysis is needed such as the outlined below.

\section{Flexibility study of the mixing tank}

Table 2 presents the nominal values and variability half-bands adopted in the case of the mixing tank. Fig. 10 shows the corresponding feasible space (without shadow). Several simulations were run to obtain that figure. In each simulation, a particular combination of disturbances was generated, equations (10)-(14) were solved, and the operability index Io was calculated to determine the operability of that point. When Io was lower than 1 , that point was marked as belonging to the feasible space. 
According to Fig. 10, the process is not operable for $T_{2}$ below $52{ }^{\circ} \mathrm{C}$ (the set point value of controller (T), a constant limit. However, the upper limit for $T_{2}$ is a function of $F_{2}$. The radius $r$ of the inscribing circle into the maximum square is equal to 0.42 . By using the corresponding cfd, it can be estimated that the maximum square covers $18 \%$ of the possible cases if every disturbance has uniform distribution. The covered cases are $44 \%$ when every disturbance follows the triangular distribution.

\begin{tabular}{c|cccc} 
& $\boldsymbol{F}_{2}\left(\mathrm{~m}^{3} / \mathbf{s}\right)$ & $\boldsymbol{T}_{2}\left({ }^{\circ} \mathrm{C}\right)$ & $x_{1}$ & $x_{3}$ \\
\hline $\boldsymbol{X} n$ & 0.02 & 80 & 0.5 & 0.5 \\
$\Delta \boldsymbol{X} n$ & 0.01 & 40 & 0.5 & 0.5
\end{tabular}

Table 2. Nominal values and half-bands of acceptable variability for the case of the mixing tank.

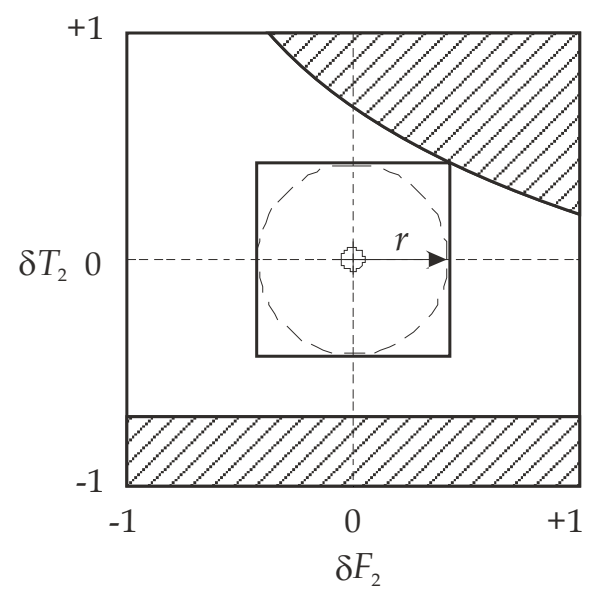

Fig. 10. Mixing tank example. Feasible space of operation (without shadow), $r=0.42$.

Fig. 11 shows the values adopted by the process variables $\mathrm{Y}$ inside the feasible space. Several simulations were run to obtain that figure (the same ones used to determine the feasible space). In each simulation, a particular combination of disturbances was generated, and the corresponding values of the process variables were calculated. If the process state thus generated belonged to the feasible space $-I o$ belonging to the interval $[0,1)-, \delta x_{1}$ and $\delta x_{3}$ were added to the plot as 'pair $n$ '.

According to Fig. 11, the most critical variable is $x_{1}$ because it reaches the limits of acceptable variability. More precisely, $\delta x_{1}$ reaches the value 1 , which means $x_{1}$ reaches its highest allowed value. Therefore, the feasible space can be expanded by acting on the sector supervised by the CT controller; e.g. increasing the size of the valve V1 or decreasing the temperature $T_{1}$. In fact, it is evident from eq. (11) that it is possible to reduce $x_{1}$ (the critical variable) by only increasing $C_{\mathrm{v} 1}$ (the size of valve V1) and without changing the other variables.

From the results of Fig. 11, it can also be deduced that the reduction of $x_{1}$ will cause that some process states become now feasible states, augmenting in this way the feasible space. This is one of the several conclusions that can be obtained from that figure and demonstrates one advantage of the proposed method. To prove that the previous conclusion 
was correct, a new test was made and the new feasible space was determined after multiplying $C_{\mathrm{v} 1}$ by two. The new feasible space thus obtained was bigger than the original one. The same conclusion was again obtained though it required many more simulations. The usefulness of the information presented by Fig. 11, a contribution of the proposed method, cannot be overemphasized.

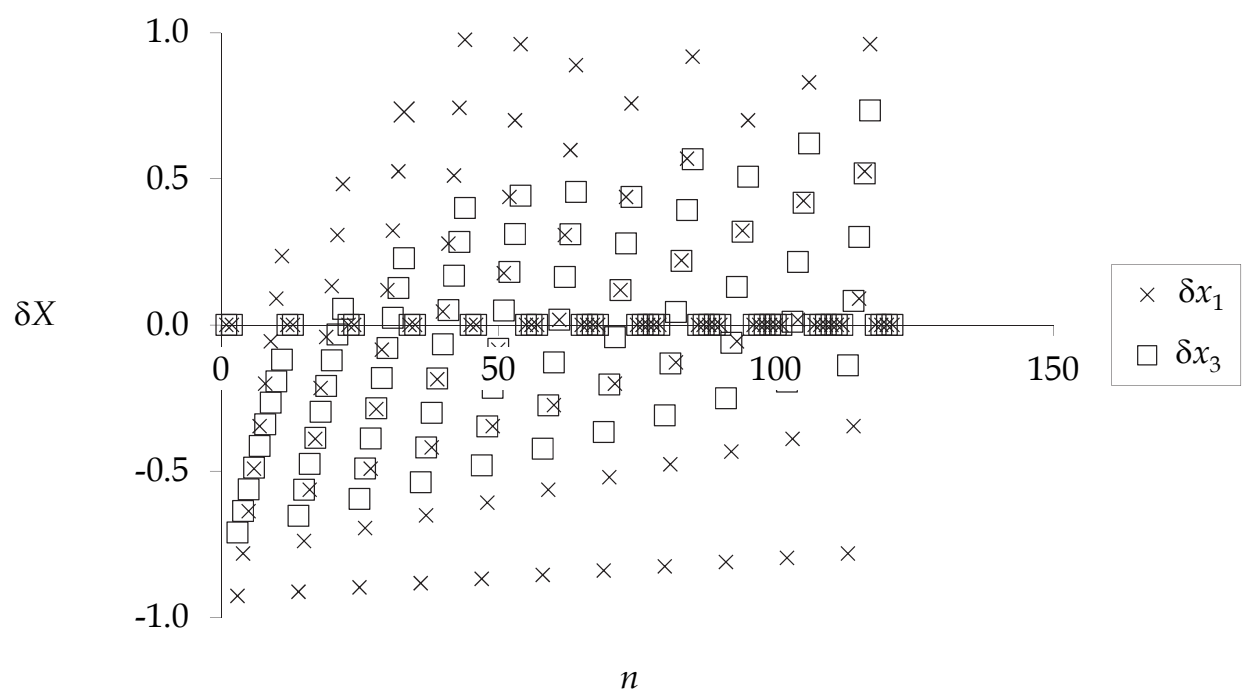

Fig. 11. Mixing tank example. Process variables in the feasible space.

Fig. 12 shows the process states corresponding to the representative points of the overall space. These points were explored by the simulations used before for defining the feasible space. The figure is a plot with parallel coordinates; this is a common way of visualizing high-dimensional geometry and analysing multivariate data. To show a set of points in an ndimensional space, a backdrop is drawn consisting of $n$ parallel lines, typically vertical and equally spaced. A point in that n-dimensional space is represented as a polyline with vertices on the parallel axes; the position of the vertex on the i-th axis corresponds to the i-th coordinate of the point. In this work, the set of represented points correspond to the studied process states, i.e. every plotted polyline represents a particular steady state. The vertical axis represents the studied variable, e.g. Fig. 12 has axis for $F_{2}, T_{2}, x_{1}$ and $x_{3}$.

In Fig. 12 every point of the overall space is depicted by a line linking the values corresponding to all the considered $\delta X$. For the sake of clarity, the vertical axis corresponding to the process variables are not drawn. Among those points only those with absolute values of $\delta x_{1}$ and $\delta x_{3}$ lower than 1 are operable and hence belong to the feasible space. That figure also shows that $x_{1}$ is the most critical variable. Moreover the strong effect of $T_{2}$ over $x_{1}$ is evident: decreasing $T_{2}$ is more risky than increasing it. $x_{1}$ is indeed the most critical variable because it has more values out of the $(-1,1)$ interval. The effect of $T_{2}$ on $x_{1}$ provokes that the polylines associated to an increase of $T_{2}$ are also associated to an increase of $x_{1}$. An equivalent but weaker relation exists between the decrease of $T_{2}$ and the decrease of $x_{3}$. This conclusion is just one of the many that be inferred from Fig. 12. This demonstrates another advantage of the proposed method. 


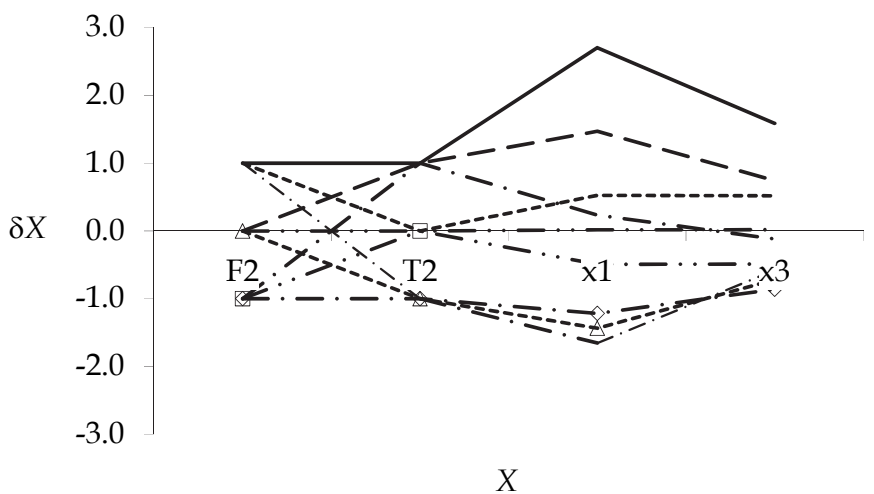

Fig. 12. Mixing tank example. Representative points of the overall space.

\section{Flexibility indexes}

Different kinds of indexes have been defined for representing the process flexibility. In general, the better the index the more complex is its calculation. That's why at the first stages of the process design simpler indexes should be used. Conversely, at the final stages of the design the most exact indexes should be calculated. In line with this reasoning several indexes were evaluated for the mixing tank. Those indexes are presented below, ordered by increasing quality and complexity.

The first index is Iv. It is equivalent to FIG (Grossmann et al., 1983) while FIG $\leq 1$. Iv is defined as:

$$
I v=r
$$

where $r$ is the radius of the circle tangential to the maximum square.

The second index is $I c$, which is defined as the ratio of the size of the maximum hypercube of dimension $n$ (maximum square if $n=2$ ) to the size of the overall space:

$$
I c=r^{n}
$$

The third index is $I r$, which is defined as the size ratio of the feasible space to the overall space -it is equivalent to FIV (Lai \& Hui, 2007)-. All the above indexes belong to the interval $[0,1]$, and the value 1 represents the maximum flexibility.

The indexes $I v$ and $I c$ are conservative because they take into account a subspace (i.e., the maximum square or hypercube) of the whole feasible space. They also rely on geometric ratios between the feasible space and the overall space. This is adequate when every disturbance follows the uniform distribution. However this is also a limitation of $I r$. For other distributions, it becomes necessary to define additional indexes. The fourth defined index would be $P c$, the probability that the disturbances yield a point inside the maximum square (or hypercube). This depends on the probability distributions of the disturbances. Equations (20) and (22) are used to calculate $P_{C}$ in the cases of uniform and triangular distributions, respectively. For other distributions, Monte Carlo simulation can be instead used, as was previously outlined for the normal distribution (Fig. 7-Fig. 9). The fifth and last index is $\mathrm{Pr}$, the probability of the disturbances yielding a point inside the feasible space. It is equivalent to SF (Pistikopoulos \& Mazzucchi, 1990), which also depends on the disturbances 
probability distributions. $\mathrm{Pr}$ is the index most difficult to calculate. In this work $\operatorname{Pr}$ was calculated by Monte Carlo simulation with 10000 samples.

Table 3 shows all the defined indexes calculated for the mixing tank example. For the calculation, it was assumed that the disturbances probability distributions were triangular. When the disturbances produced a point into the feasible space, the process was by definition considered operable at those conditions. Therefore, the higher the probability of the disturbances yielding a feasible point the higher the probability of the process of being operable -i.e., the process is more flexible-. From all the indexes presented in Table 3 the more realistic and useful is $\mathrm{Pr}$, which represents the probability that the process be operable. While the value 0.88 may prove enough for some experts, this can be improved by expanding the feasible space as it was done when studying Fig. 11 and Fig. 12.

\begin{tabular}{ccccc} 
Iv & Ic & Ir & Pc & Pr \\
\hline 0.42 & 0.18 & 0.68 & 0.44 & 0.88
\end{tabular}

Table 3. Flexibility indexes of the mixing tank.

As stated before almost all the indexes, except $P r$, are conservative. The values reported in Table 3 show how conservative these indexes can be. For example, Ic assigns a value of 0.18 to the mixing tank, suggesting a rather poor flexibility; $P r$, in contrast, assigns a much better value. The difference between these values is a strong evidence of the convenience of utilizing $\operatorname{Pr}$ for flexibility studies.

\section{MSF modelling}

The strategy proposed for performing flexibility studies was applied to the analysis of a MSF desalination plant (Fig. 13). This kind of plant has a series of flash units (stages) where sea water is evaporated to obtain distilled water. The plant has $N$ stages; the first $M$ ones belong to the recovery section and the remaining ones belong to the rejection section. There are also six $\mathrm{P}+\mathrm{I}$ controllers that set the operating conditions for the heater, the feed, the recycle and the level of the last stage.

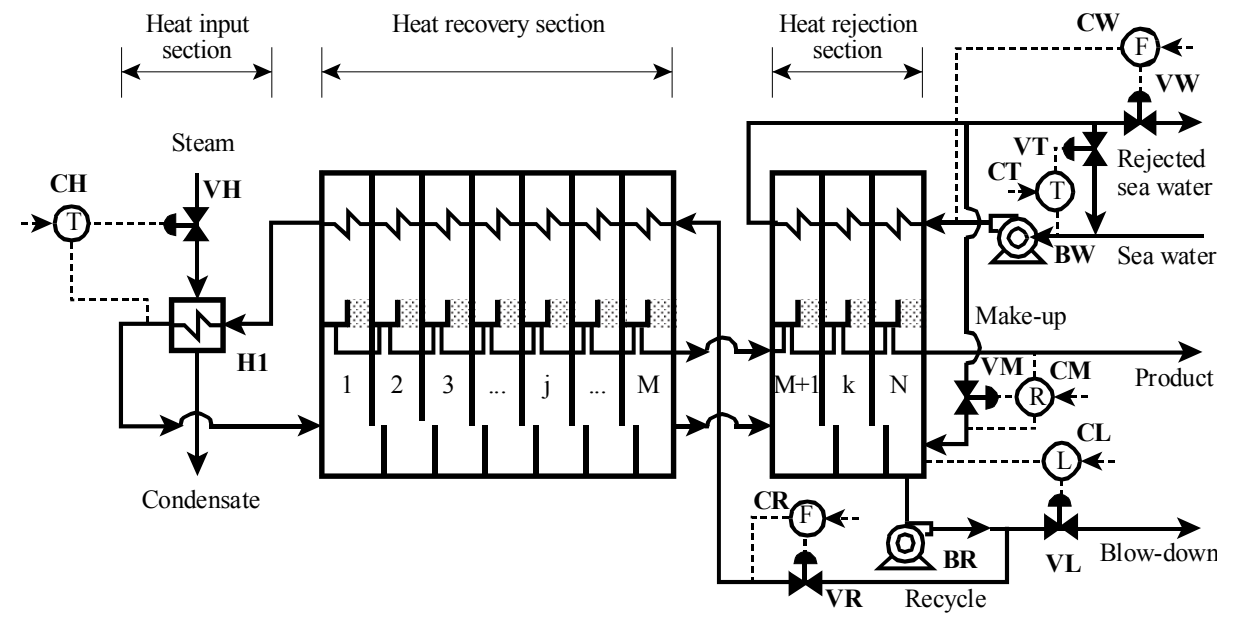

Fig. 13. Simplified scheme of the studied MSF plant. 
For the dynamic model of the MSF plant an early model developed by Tarifa and Scenna (2001) was used. This comprises a set of ordinary differential equations and a set of algebraic equations. The steady model was obtained by setting to 0 every derivative term. The model parameters were adjusted to represent the system studied by Thomas et al. (1998). This system has 15 stages in the recovery section and 3 stages in the rejection section. Table 4 shows the adopted operating conditions.

\begin{tabular}{c} 
Sea water: \\
$T s w=28^{\circ} \mathrm{C}$ \\
$X s w=51500 \mathrm{ppm}$ \\
\hline Vapour: \\
$P v h=0.937 \mathrm{~atm}$ \\
\hline Controller set points: \\
T0s $=90^{\circ} \mathrm{C}$ \\
$L s=0.6 \mathrm{~m}$ \\
Wcws $=14800 \mathrm{tn} / \mathrm{h}$ \\
Tcws $=33^{\circ} \mathrm{C}$ \\
$R m u s=4.6$ \\
Wbs $=14380 \mathrm{tn} / \mathrm{h}$ \\
\hline
\end{tabular}

Table 4. MSF plant. Operating conditions.

\section{Flexibility study of the MSF plant}

The disturbances considered were the seawater temperature $T s w$ and the seawater salinity $X s w$. These variables show a wide range of variability and they have large effects on the operation of MSF plants (Tanvir \& Mujtaba, 2006). The studied process variables were those presented in Table 5 .

\begin{tabular}{c}
\hline$A L:$ output of $\mathrm{CL}$ \\
$A W m u$ : output of $\mathrm{CM}$ \\
$A T 0:$ output of $\mathrm{CH}$ \\
$A T c w:$ output of $\mathrm{CT}$ \\
$A W b:$ output of $\mathrm{CR}$ \\
$A W c w:$ output of $\mathrm{CW}$ \\
\hline
\end{tabular}

Table 5. MSF plant. Process variables selected for the study.

Table 6 shows the nominal values and half-bands of variability adopted for the MSF plant. For each process variable, its half-band of variability $\Delta X n$ was set equal to $80 \%$ of the corresponding nominal value $\mathrm{X} n$.

\begin{tabular}{c|cccccccc} 
& $\boldsymbol{T s w}\left({ }^{\circ} \mathrm{C}\right)$ & $X s w$ & $A L$ & $A W m u$ & $A T 0$ & $A T c w$ & $A W b$ & $A W c w$ \\
\hline $\boldsymbol{X n}$ & 30 & 0.0515 & 0.35 & 0.42 & 0.54 & 0.32 & 0.53 & 0.22 \\
$\Delta \boldsymbol{X} n$ & 5 & 0.0165 & 0.28 & 0.34 & 0.43 & 0.26 & 0.42 & 0.18
\end{tabular}

Table 6. MSF plant. Nominal values and half-bands of acceptable variability. 
Fig. 14 shows the feasible space (without shadow) of operation of the MSF plant. That feasible space was obtained by simulation, a process that proved time consuming due to the model complexity. The simulations were performed taking samples in steps of 0.20 for both $\delta X s w$ and $\delta T s w$. The radius $r$ of the circle inside the maximum square was equal to 0.40 . According to the simulations the process was not operable for values of Tsw higher than $33^{\circ} \mathrm{C}$ (constant limit, also the set point value of the CT controller). On the other side, the lower limit for Tsw was a function of Xsw. The upper limit of Tsw corresponded to a value of $r$ of 0.60 . Therefore the actual radius belonged to the interval $[0.40,0.60)$. Taking the worst case, $r$ becomes equal to 0.40 . By using the corresponding cfd it was estimated that the maximum square covered $16 \%$ of the possible cases when every disturbance had uniform distribution. The covered cases were $41 \%$ when every disturbance followed the triangular distribution.

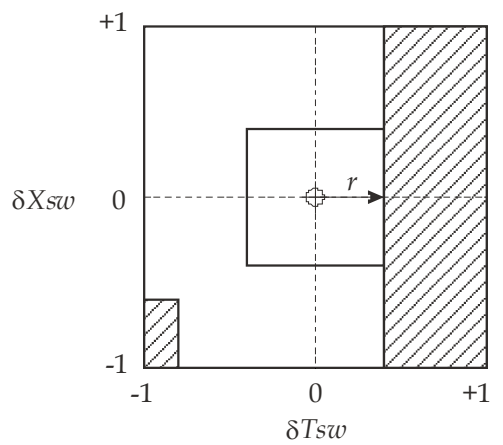

Fig. 14. MSF plant. Feasible space (without shadow) for $r=0.40$.

Fig. 15 presents the values adopted by some of the analysed process variables inside the feasible space. The remaining ones were not plotted because their changes were not meaningful. The most critical variable are ATcw and AWcw because they reach the limits of acceptable variability; therefore, the feasible space can be expanded by acting on the sectors supervised by the controllers CT and CW (e.g. increasing the size of corresponding valves).

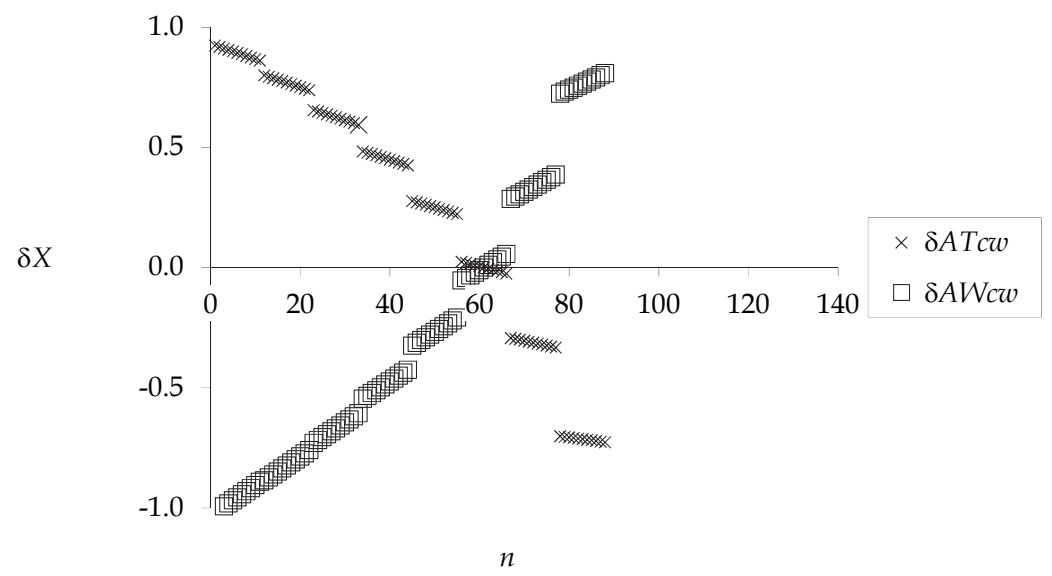

Fig. 15. MSF plant. Process variables in the feasible space. 
Fig. 16 shows representative points of the overall space of operation of the MSF plant. Every point is depicted by a line linking the values corresponding to all the considered $\delta X$. Of those points, only those with absolute values of $\delta A T c w$ and $\delta A W c w$ lower than 1 are operable. The figure also shows that both process variables, ATcw and AWcw, are critical. Moreover, the strong effect of Tsw on $A T c w$ and $A w c w$ is evident. Increasing Tsw values are more risky than decreasing ones.

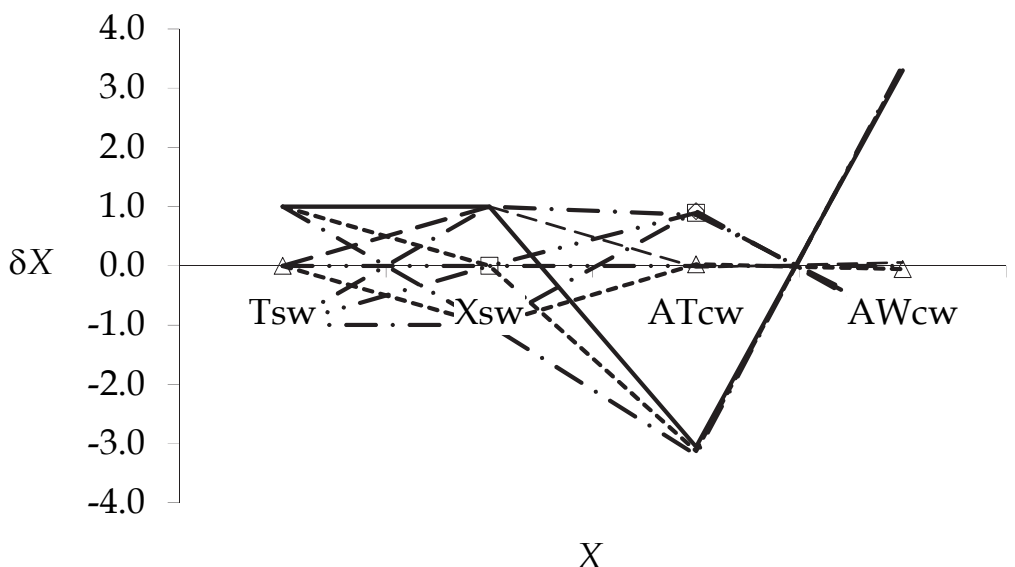

Fig. 16. Representative points of the overall space for the MSF plant.

Finally, Table 7 shows the previously defined indexes as calculated for the case study of the MSF plant. In the calculation triangular distributions for the disturbances were again assumed.

\begin{tabular}{ccccc} 
Iv & Ic & Ir & Pc & Pr \\
\hline 0.40 & 0.16 & 0.68 & 0.41 & 0.82
\end{tabular}

Table 7. MSF plant flexibility indexes.

\section{Conclusion}

A strategy for performing a flexibility study was presented and it was applied to an introductory simple example and to a complex case study of a multistage flash plant. The strategy begins with the development of a steady-state model of the analysed process. Next, the main disturbances and process variables are identified. Those variables are then properly standardized. The feasible space is determined by simulation. At this point, a set of indexes can be evaluated and the process flexibility estimated.

The proposed methodology allows to calculate the probability associated to the feasible space. It also enables the identification of the critical variables of the process; which can then be modified at the implementation level (changing equipment design parameters) in order to increase the flexibility. The inverse problem can also be considered, i.e. determining the effects on the process flexibility produced by a modification of some components or parameters of the plant. Then, the new feasible space, its new associated probability and the involved costs will together establish the convenience of such modification. 


\section{Acknowledgement}

The authors wish to acknowledge the financial support of the Consejo Nacional de Investigaciones Científicas y Técnicas CONICET (Argentina) and Universidad Nacional de Jujuy UNJu (Argentina).

\section{References}

Grossmann, I.E., Halemane, K.P. \& Swaney, R.E. (1983). Optimization Strategies for Flexible Chemical Processes. Computers E Chemical Engineering, Vol. 7, No. 4, pp. 439-462, ISSN 0098-1354

Lai, S.-M. \& Hui, C.-W. (2007). Measurement of plant flexibility. Computer Aided Chemical Engineering, Vol. 24, pp. 189-194, ISSN 1570-7946

Metropolis, N. \& Ulam, S. (1949). The Monte Carlo Method. Journal of the American Statistical Association, Vol. 44, No. 427, (September 1949), pp. 335-341, ISSN 0162-1459

Pistikopoulos, E.N. \& Mazzucchi, T.A. (1990). A Novel Flexibility Analysis Approach for Processes with Stochastic Parameters. Computers \& Chemical Engineering, Vol. 14, No. 9, (September 1990), pp. 991-1000, ISSN 0098-1354

Rose, C. \& Smith, M.D. (2002) Mathematical Statistics with Mathematica, Springer-Verlag, ISBN 9780387952345, New York, USA

Rubinstein, R.Y. \& Kroese, D.P. (2007) Simulation and the Monte Carlo Method (second edition), John Wiley \& Sons, ISBN 9780470177945, Hoboken, USA

Saboo, A.K., Morari, M. \& Woodcock, D.C. (1985). Design of Resilient Processing Plants-VIII: A Resilience Index for Heat Exchanger Networks, Chemical Engineering Science, Vol. 40, No. 8, pp. 1553-1565, ISSN 0009-2509

Tanvir, M.S. \& Mujtaba, I.M. (2006). Neural network based correlations for estimating temperature elevation for seawater in MSF desalination process. Desalination, Vol. 195, No 1-3, (August 2006), pp. 251-272, ISSN 0011-9164

Tarifa, E.E. \& Scenna, N.J. (2001). A Dynamic Simulator for MSF Plants. Desalination, Vol. 138, No. 1-3, (September 2001), pp. 349-364

Thomas, P.J., Bhattacharyya, S., Patra, A. \& Rao, G.P. (1998). Steady state and dynamic simulation of multi-stage flash desalination plants: A case study. Computers $\mathcal{E}$ Chemical Engineering, Vol. 22, No. 10, (September 1998), pp. 1515-1529, ISSN 0098-1354

Weitz, O. \& Lewin, D.R. (1996). Dynamic Controllability and Resiliency Diagnosis Using Steady State Process Flowsheet Data. Computers \& Chemical Engineering, Vol. 20, No. 4, (April 1996), pp. 325-335, ISSN 0098-1354 


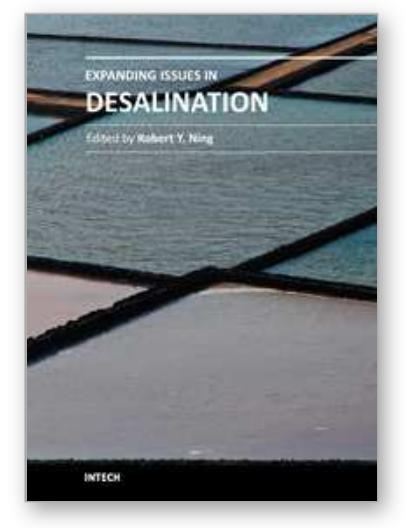

\author{
Expanding Issues in Desalination \\ Edited by Prof. Robert Y. Ning
}

ISBN 978-953-307-624-9

Hard cover, 412 pages

Publisher InTech

Published online 22, September, 2011

Published in print edition September, 2011

For this book, the term â€œdesalinationâ€ is used in the broadest sense of the removal of dissolved, suspended, visible and invisible impurities in seawater, brackish water and wastewater, to make them drinkable, or pure enough for industrial applications like in the processes for the production of steam, power, pharmaceuticals and microelectronics, or simply for discharge back into the environment. This book is a companion volume to â€œDesalination, Trends and Technologiesâ€, INTECH, 2011, expanding on the extension of seawater desalination to brackish and wastewater desalination applications, and associated technical issues. For students and workers in the field of desalination, this book provides a summary of key concepts and keywords with which detailed information may be gathered through internet search engines. Papers and reviews collected in this volume covers the spectrum of topics on the desalination of water, too broad to delve into in depth. The literature citations in these papers serve to fill in gaps in the coverage of this book. Contributions to the knowledge-base of desalination is expected to continue to grow exponentially in the coming years.

\title{
How to reference
}

In order to correctly reference this scholarly work, feel free to copy and paste the following:

Enrique Tarifa, Samuel Franco Dominguez, Carlos Vera and Sergio Mussati (2011). Flexibility Study for a MSF by Monte Carlo Simulation, Expanding Issues in Desalination, Prof. Robert Y. Ning (Ed.), ISBN: 978-953-307624-9, InTech, Available from: http://www.intechopen.com/books/expanding-issues-in-desalination/flexibilitystudy-for-a-msf-by-monte-carlo-simulation

\section{INTECH}

open science | open minds

\section{InTech Europe}

University Campus STeP Ri

Slavka Krautzeka 83/A

51000 Rijeka, Croatia

Phone: +385 (51) 770447

Fax: +385 (51) 686166

www.intechopen.com

\section{InTech China}

Unit 405, Office Block, Hotel Equatorial Shanghai

No.65, Yan An Road (West), Shanghai, 200040, China

中国上海市延安西路65号上海国际贵都大饭店办公楼 405 单元

Phone: +86-21-62489820

Fax: $+86-21-62489821$ 
(C) 2011 The Author(s). Licensee IntechOpen. This chapter is distributed under the terms of the Creative Commons Attribution-NonCommercialShareAlike-3.0 License, which permits use, distribution and reproduction for non-commercial purposes, provided the original is properly cited and derivative works building on this content are distributed under the same license. 